\title{
Analysis of Canadian Consumer Spending Patterns towards Green Products
}

\author{
Hossein Ataei ${ }^{1} \&$ Farnaz Taherkhani ${ }^{2}$ \\ ${ }^{1}$ Syracuse University, Syracuse, New York, USA \\ ${ }^{2}$ Sultan Qaboos University, Muscat, Sultanate of Oman \\ Correspondence: Hossein Ataei, Syracuse University, 151 Link Hall, Syracuse, NY, 13244, USA. Tel: \\ 1-315-443-9599. E-mail: hataei@syr.edu
}

\author{
Received: February 13, 2015 Accepted: March 4, 2015 Online Published: March 28, 2015 \\ doi:10.5539/ijms.v7n2p19 URL: http://dx.doi.org/10.5539/ijms.v7n2p19
}

\begin{abstract}
This paper aims to investigate the consumer behavior towards purchasing environmentally-friendly or "green" products from marketing analysis and consumer price sensitivity standpoints.

The experimental methodology in this paper is based on statistical analysis of the survey questionnaire results and in-depth interviews with Canadian consumers. This paper indicates that a majority of consumers see added-value for environmentally-friendly products. The spending patterns are studied for different product price groups across customers of different age and genders. Moreover, analysis ofthe consumer price-sensitivityresults for green alternatives and different product categories,it demonstrates that the consumers attribute higher importance tothe green products that have more individual monetary benefits (e.g., energy-efficient products) over the oneswith more social and environmental benefits such as biodegradable products. This article also looks into the existing differences between gender and age groups inthis regards.

Adding the "green" dimension to original purchasing decision-making triangle of price - quality - brand, the findings of this paper illustrate on how the consumer behavior and priorities would differ for lower-end household items compared to more expensive products such as appliances and electronics.

Theseresults provide valuable insight to manufacturers, product managers and marketing directorstoefficiently price and innovatively market their greenproducts without negatively impacting the salesor compromising the profits.
\end{abstract}

Keywords: Canadian customers, green products, spending patterns, sustainability, marketing analysis

\section{Introduction}

Over the past decade, there has been an increasing focus on environmental awareness from almost every aspect of daily lives including the educational campaigns to national and international policy-makings and to consumables.The grocery stores now devote more "shelf space" to organic groceries and in almost all major cities across North America,supplying of free plastic bags to customers is discontinued.

According to the survey results of the report, A Green Economy for Canada: Consulting with Canadians, consumers approach the term "green" with different perspectives that range from concerns over climate change; interest in a consumer-benefitting leverage mechanisms between the environment and economic gains; future opportunities for innovations in manufacturing eco-friendly products and to an increasing desire for more product diversification and risk minimization. According to the same survey results, approximately $60 \%$ of the respondents indicated their expectations for a smooth transition towards a "green economy" through making significant economic and social gains. Canadian consumers suggested development of an advanced national dialogue and a shared vision alongside with the United Nations Global Sustainable Development Report as well as establishment of clear pricing strategies for goods and services followed by more investments in R\&D initiatives in green businesses.

The importance of assessing consumer willingness for extra expenditure over environmentally-friendly items is in determining whether consumers will actually change their spending habits as a result of the increased awareness on these products and their publicized benefits in the recent years. 
Product Managers and Marketing Directors always look for means to understand the extent of consumers' willingness to pay extra for green products. In the absence of a comprehensive statistical study on consumer spending willingness, companies may make costly product-pricing decisions. Moreover, the product managers might not thoroughly understand whether the incurred extra costs towards environmentally-friendly products are likely to result in a significant return on investment. That said, this paper is aiming to provide insights into this area by statistical analysis and hypothesis testing of the collected data through the distributed survey questionnaires.

\section{Method}

In this study, the term "green" refers to environmental aspects of a product, such as being organic, biodegradable, low carbon monoxide emitting, etc. The objective is to use the analysis of the collected survey results and the focus group discussions to determine statistically-relevant patterns or data correlations to investigate whether consumers are really willing to spend more on green products; especially how much more and for which product categories.

\subsection{Survey Questionnaire and Data Collection}

The survey questionnaire that is used for collecting the data covers wide range of questions and topics. These topics range from consumer price sensitivity in purchasing green products to the relative importance of a product's environmental impact or friendliness compared to other purchase decision-making dimensions such as price, brand, quality, and convenience. Through statistical analysis of the results, both qualitatively and quantitatively, we investigated whether price sensitivity is a constant factor for products that are of the same type and price range or it varies between similar products. Moreover, we studied the consumer price sensitivity on green products with regards to the consumer gender and age groups, education levels and other socio-economic and demographical classifications.

A total of 41 survey questionnaires and focus group interviews were collected for data analysis purposes. In order to achieve the highest possible random sampling, the survey questionnaires were distributed in different environments (e.g., workplaces, schools and shopping malls) in order to collect data from broader range of respondents varying based on age, gender, education, and income levels.

The analysis results will be useful to product development and marketing firms both in planning and pricing of new products as well as in product-pricing reviews for existing products. Further understanding of consumer behavior and their spending habits on green products, may also be beneficialin innovative investment strategies in developing other eco-friendly products.

\section{Survey Results Analysis}

Answering thebasic question of whether the consumers perceive a product that is promoted as environmentally-friendly or "green" actually adds extra value tothe product, with a 95\% confidence interval, $71 \%-94 \%$ of consumers (a mean of $83 \%$ of respondents) believedso. Therefore, there is a significant incentivein marketing a product as "green", at least in a first instance.

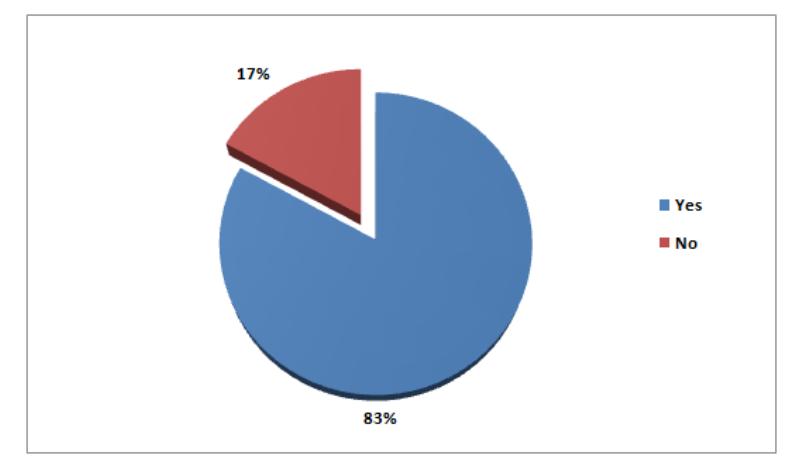

Figure 1. Consumer perception towards green products' "added value"

\subsection{Extra Spending on Green Products}

With regards to the extra amounts that consumers are willing to spend for environmentally- friendly products, according to the conducted survey sampling, the following conclusions are made with $90 \%$ confidence interval across four consumer spending patterns studied: (1) the consumer does not pay extra for acquiring the green 
product alternative; (2) the consumer is willing to pay between $10 \%$ to $29 \%$ more than regular price tag for the green product; (3) the extra payment amount for green product ranges between $30 \%$ to $49 \%$ more and (4) the consumer tends to spend $50 \%$ or more to obtain the environmentally-friendly product.

Moreover, five distinguished product price groups were introduced and used in this paper for analysis of the survey results: (1) products that are priced less than $\$ 5$; (2) $\$ 6$ to $\$ 20$ products; (3) products that cost $\$ 21$ to $\$ 100$; (4) products with $\$ 100$ - $\$ 1,000$ price tag and (5) over $\$ 1,000$ product price category.

For products under $\$ 5,33 \%$ to $59 \%$ of the consumers are willing to pay slightly more (10\% to $29 \%$ more) than the original ticket price.For products between $\$ 5$ and $\$ 20,33 \%$ to $59 \%$ of the population is willing to pay slightly more (from $10 \%$ to $29 \%$ ) than the original price. For products costing $\$ 21$ to $\$ 100,46 \%$ to $71 \%$ of consumers are willing to pay slightly more (from $10 \%$ to $29 \%$ ) than comparable non-green products. The results of the survey indicate that for products costing $\$ 100$ to $\$ 1001,48 \%$ to $74 \%$ of consumers are willing to pay slightly more (from $10 \%$ to $29 \%$ ) compared to "non-green" products. Finally, for products that cost more than $\$ 1000,43$ to $69 \%$ of the population will pay slightly more (from $10 \%$ to $29 \%$ ) for the "green" alternatives. It is important, however, to note that across product price groups most consumers are willing to pay slightly more (from $10 \%$ to $29 \%$ ) than the original item ticket price.

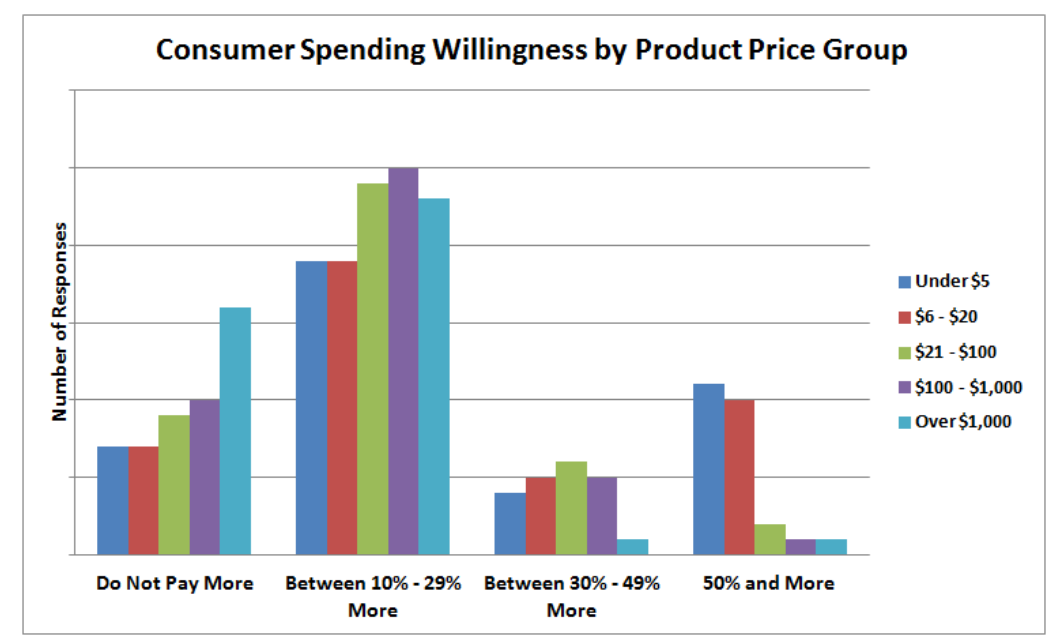

Figure 2. Consumer willingness to spend more on green products based on price

As illustrated in Figure 2, in marketing of the green products, it is safer to charge slightly more for products that are priced between $\$ 21$ and $\$ 100$ compared to more expensive products given the higher costs associated with production of greeneralternatives.Therefore, in addition to receiving incentives from various health and environmental agencies, the manufacturing companies may be able to pass along the costs of their green products to consumers in cases that the consumers find the environmental-friendlinessto be an important product feature and so they will be willing to pay slightly more for such.

According to the survey results that are illustrated in Figure 2, consumers feel more comfortable to spend $50 \%$ or more on products that cost less than $\$ 20$. As the product price increases, the percentage of consumers who are willing to pay more for green products decreases. At a $90 \%$ confidence level, it is only between $15 \%$ and $38 \%$ of consumers who are willing to spend $50 \%$ or more towards obtaining green product alternatives. However, with a $90 \%$ confidence interval, it is only up to $6 \%$ of consumers who are willing to spend $50 \%$ or more on greener alternativesof the products that initially cost more than $\$ 100$.

Marketing companies and the manufacturers need todetermine whether the price increase is sufficient to counterbalance the much smaller green savvytarget market. In other words, product developers need to carefully consider consumer willingness to spend more for greener alternatives in pricing their products in order not to risk losingtheir customer base when raising the prices. The potential customer base loss due tosuchprice increases may not always offset the increase in revenues that are expected from the highly-priced environmentally-friendly products considering the potential limited market existence.

In spite of the fact thatgreen products are supported by educational and marketing campaigns that promote the products' positive environmental impacts, however, it is only expected that a smaller segment of the general population be willing to pay higher prices for such products. 


\subsection{Consumer Spending Patterns and Age}

In order to investigate the correlation between consumer age groups and the spending tendencies towards green products, the consumer willingness to spend more on green products with different pricetags is further analyzed by creating two distinguished age groups: (1) younger consumers who have less than 35 years of age; (2) consumers who are 35 years and more. Figure 3illustrates the consumer spending breakdown for household green alternatives of less than $\$ 20$ for both customer age groups of younger and older than 35 years. Figure 4 , however, demonstrates the consumer spending willingness for all studied product price groups across the both age groups.

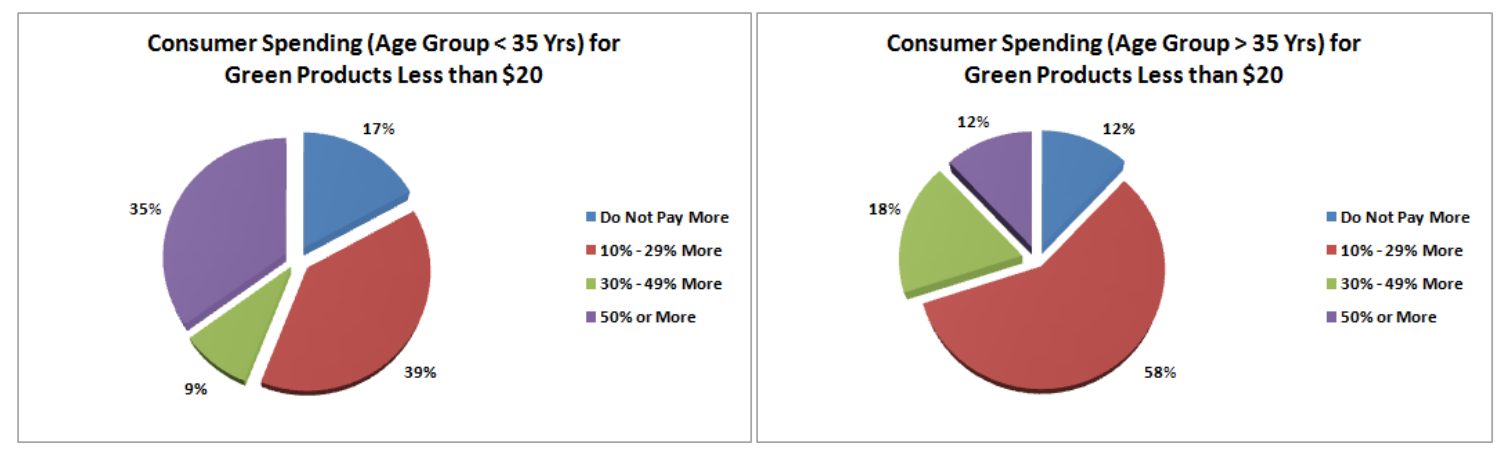

Figure 3. Consumer spending breakdown for green alternatives of less than $\$ 20$ for both customer age groups: (left) less than 35 years; (right) 35 years and more

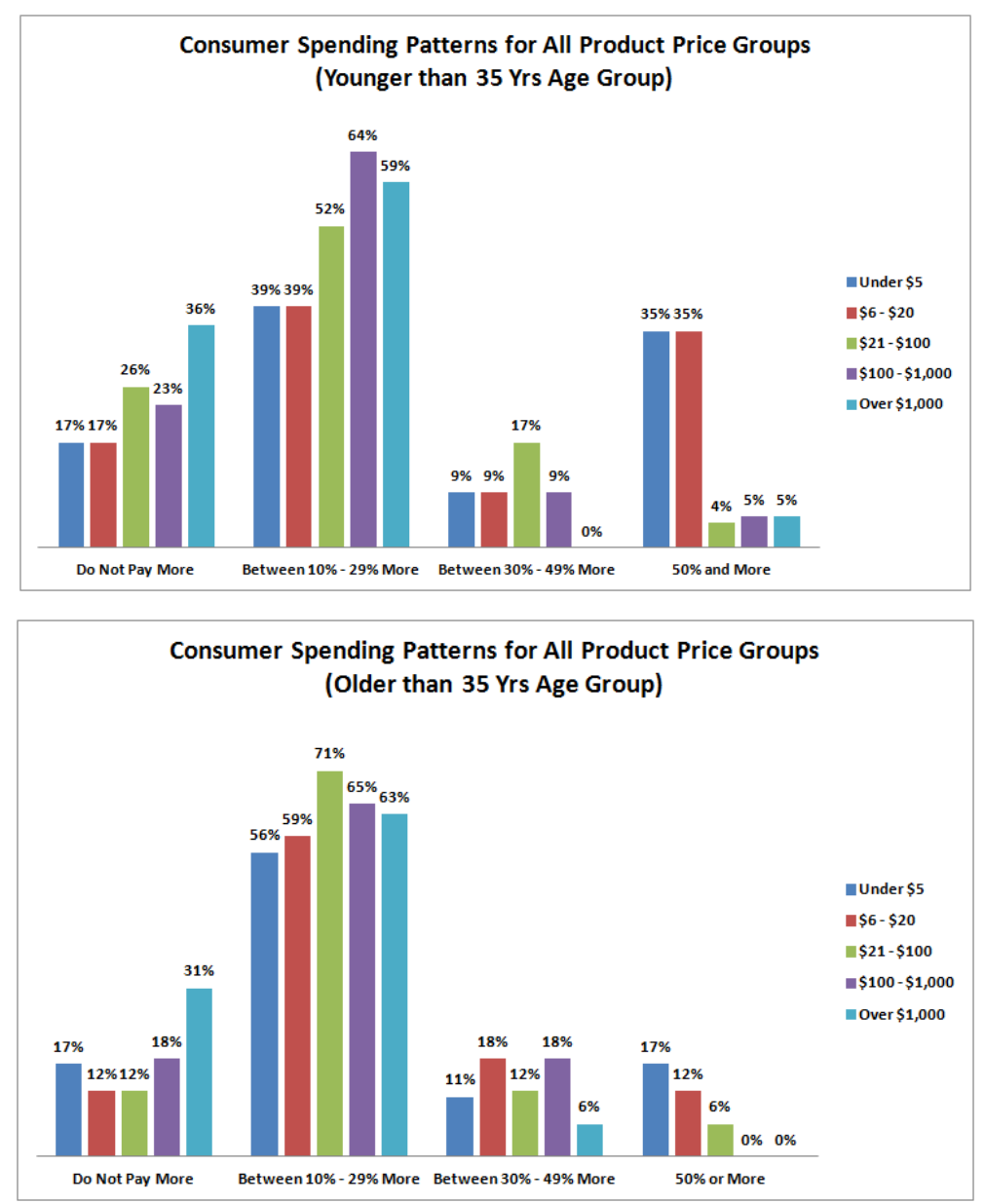

Figure 4. Consumer spending breakdown for green alternatives of all product prices across both customer Age Groups: (above) less than 35 years; (below) 35 years and more 
Both Figures 3 and 4 illustrate that the consumers who have 35 years or less demonstrate increased diversity in their spending habits. The consumer spending willingness for green alternatives among these customers is significantly higher compared to the consumers who are 35 years or older. For instance, based on the studied sample, on products with price range of $\$ 5$ to $\$ 20,35 \%$ of the younger consumers are willing to spend $50 \%$ or more for greener options compared with only $12 \%$ of those older than 35 years. On the other hand, when looking at products with price range of $\$ 5$ to $\$ 20$, at a $90 \%$ confidence interval, $43 \%$ to $63 \%$ of consumers 35 years and older will pay $10 \%$ or more for these products compared to only $27 \%$ to $52 \%$ of consumers under 35 .

Therefore, despite the fact that the consumers of the younger age group place higher importance on green product alternatives, however, they might be more budget-conscious due to possible smaller disposable income levels that bars them from spending more on green products compared to the older age groups. That said, when targeting this age group, it is important to develop green alternatives that are also competitively- priced.

Given the greater willingness amongst the older clientele to spend more on green products, there exists a higher profit margin in manufacturing and marketing the environmentally-friendly goods and alternatives that primarily target this consumer age group. The results of spending patterns analysis with focus on different age groups further confirm that although many environmental movements and awareness campaigns are youth-based, however, such initiatives need to be supported with consumer wallets through more willingness to spend on green product alternatives.

\subsection{Consumer Spending Patterns and Gender}

Consumer spending patterns in relation to gender is also studied and further investigated. Figures 5 and 6illustrate on the extra amounts that both male and female consumers spend on green alternatives for two different product price categories of $\$ 20$ - $\$ 100$ and also for high-ticket items priced at over $\$ 1,000$.

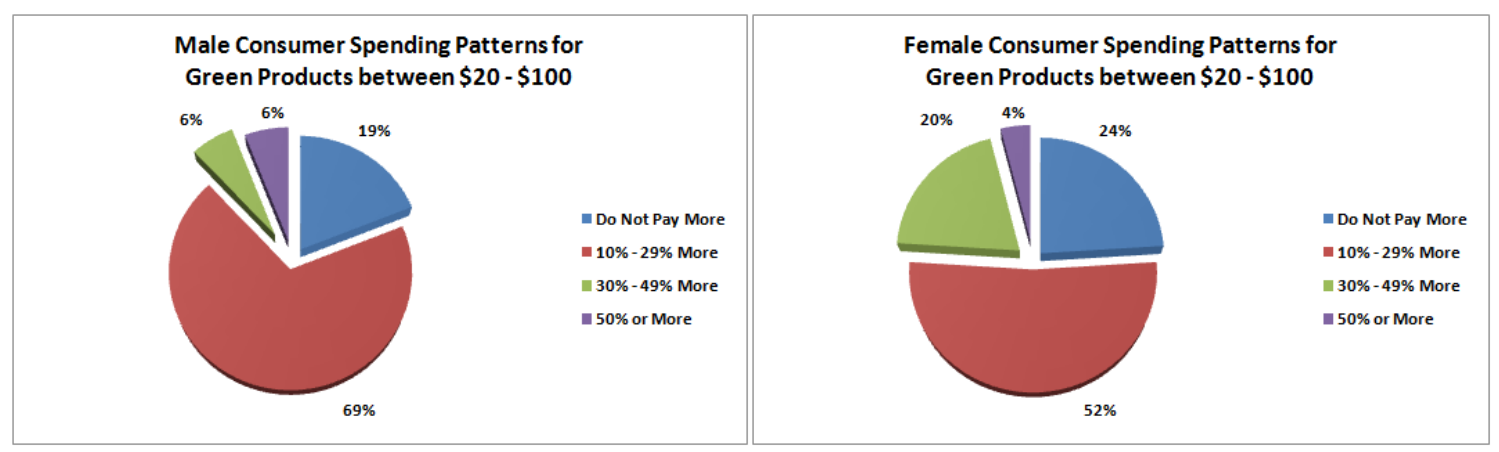

Figure 5. Consumer spending breakdown for green alternatives of $\$ 20$ - $\$ 100$ for both genders: (left) Male consumers; (right) Female consumers

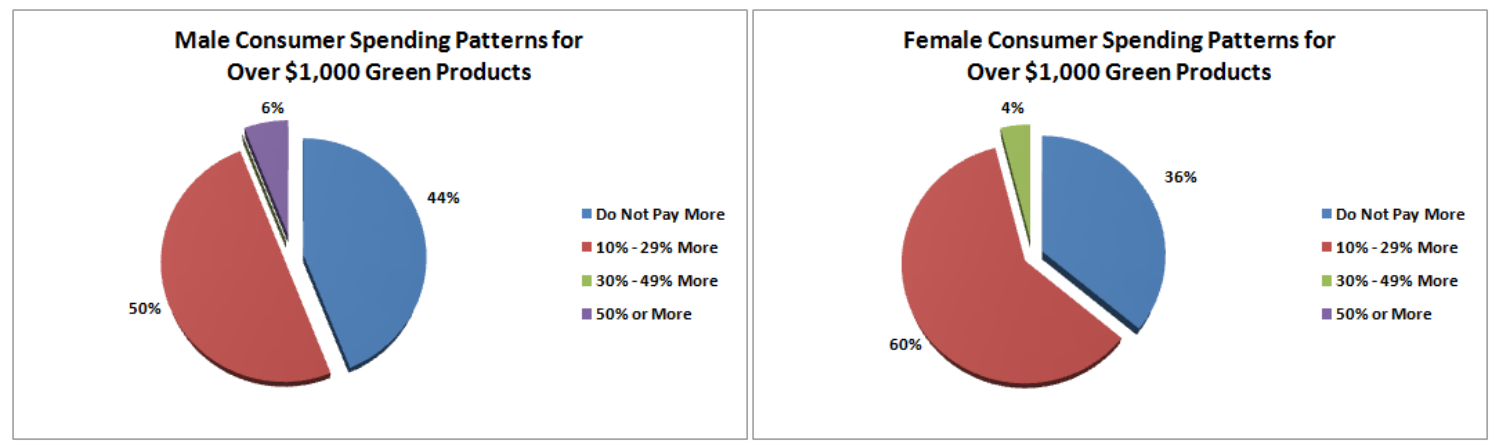

Figure 6. Consumer spending breakdown for green alternatives of over $\$ 1,000$ for both genders: (left) Male consumers; (right) Female consumers

Moreover, Figure 7 demonstrates the consumer spending willingness of both male and female consumers towards all studied five product price groups. As it is shown in the Figure, in general, women are less likely to spend extra for green goods under $\$ 1,000$ compared to men. Men are more likely to spend more than $30 \%$ extra for green product alternatives for items under $\$ 1000$. For products in the range of $\$ 20$ to $\$ 100$, at a $90 \%$ 
confidence interval, $56 \%$ to $81 \%$ of men are willing to pay more for the greener product. On the other hand only $39 \%$ to $65 \%$ of women are willing to pay any extra amount for products in the same price range.

On high-ticket items (products priced at over $\$ 1,000$ ), however, women are more likely to spend $47 \%-\% 73$ compared to the men who spend $37 \%$ to $63 \%$ extra to obtain green alternative for such items.

These results indicate that there seems to be a difference in the spending patterns of male and female consumers towards green products. This is an essential point to consider with regards to the products or marketing efforts that are gender-specific. Manufacturers and marketing managers may opt in different pricing strategies given the primary target market (males or females) for specific green product alternatives.
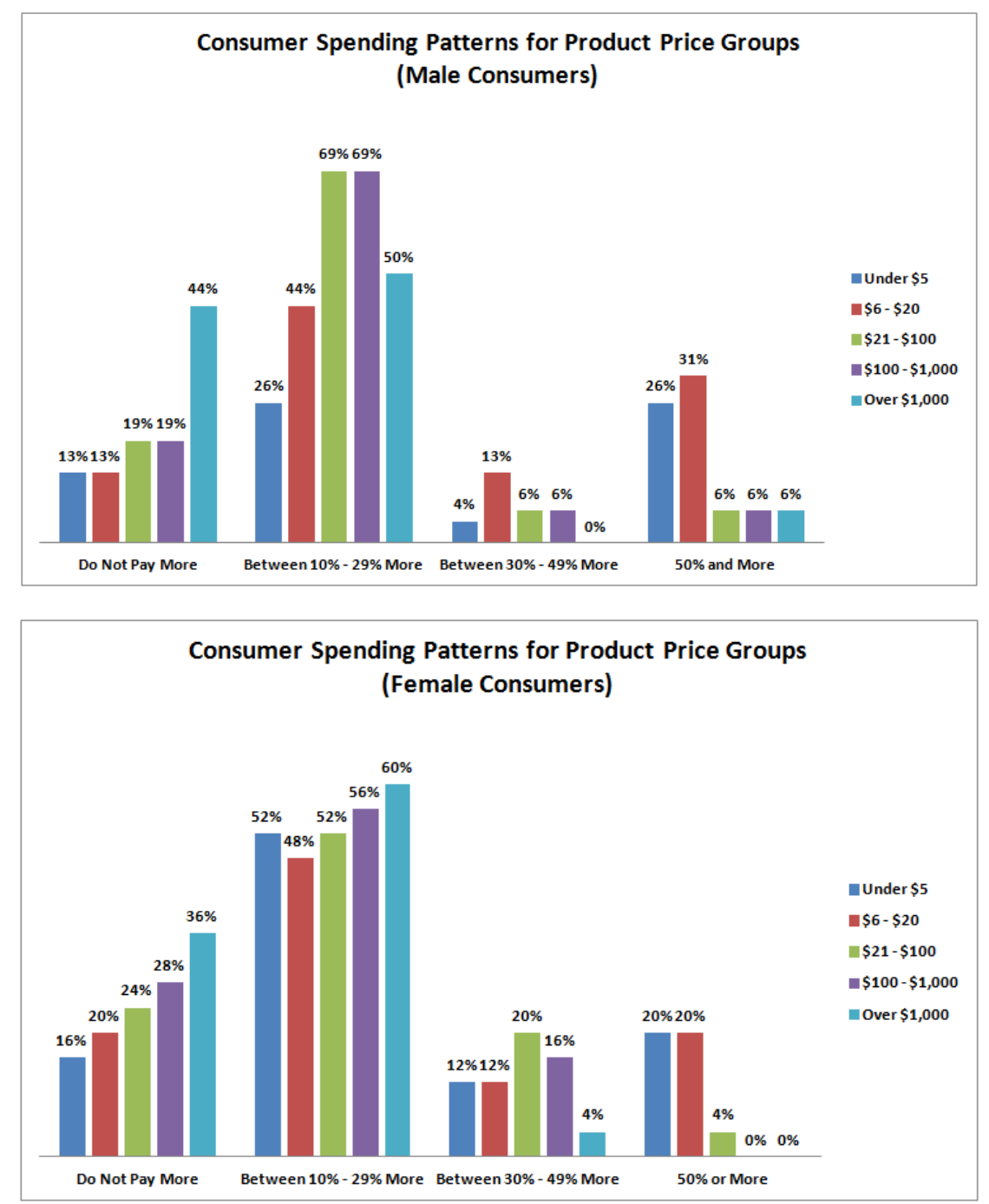

Figure 7. Consumer spending breakdown for green alternatives of all product prices across both genders: (above) Male consumers; (below) Female consumers

\subsection{Product Features and Consumer Purchase Decision Matrix}

In furthering the spending patterns analysis into the relative importance of various product features (brand, quality, price, convenience, and environmental impact/friendliness), two different product categories were identified and investigated: (i) cleaning products and (ii) electronics. These two product categories were selected based on their positioning on the product-price spectrum with household cleaning itemsto be placed in the lower end of the spectrum compared to the electronics that are positioned among the high-priced household goods. The results of the survey indicate that the environmental friendliness feature for household cleaning products was only more important than the product brand when compared against all other product category features. On 
the other hand, for electronics, the results showed that the environmental friendliness feature was not more important than any of the other features. These results seem to indicate that for lower-price items such as cleaning products, environmental-friendliness feature does at least have more weight over the brand in the consumer purchase decision matrix. In contrast, when it comes to high-priced products such as electronics, environmental impact/friendliness is the least important of the product features in consumer's purchase decision matrix compared against price, brand, and convenience.

\subsection{Spending Patterns Based On Personal Benefits versus Environmental Impacts}

The other part of the spending patterns analysis is to assess the consumer willingness to pay extra for green product alternatives that either personally affect the customer (e.g., such as a fuel-efficient vehicles) or benefit the environment as a whole (e.g., biodegradable products). Figure 8 illustrates on the consumer spending willingness on environmentally-friendly products that either directly benefit the consumer or affect the environment holistically based on a scoring system of 1 (least willing to spend extra) and 10 (most willing to pay more).

It is shown that people rated their willingness to pay more for products that affected them personally higher than their willingness to pay more for products that affect the environment only. When the analysis was further broken down by consumer gender groups between male and female groups, there was no significant statistical difference in extra spending mean values between the two genders for green alternatives that directly affect the consumers.

Moreover, there is also no significant difference existing between men and women regarding their spending patterns towards the environmentally friendly products that have a holistic positive impact on the environment. Therefore, the manufacturers and marketing managers may take advantage of the fact that consumers slightly spend more on green products that directly and personally affect them in comparison with green alternatives that mainly impact the environment.
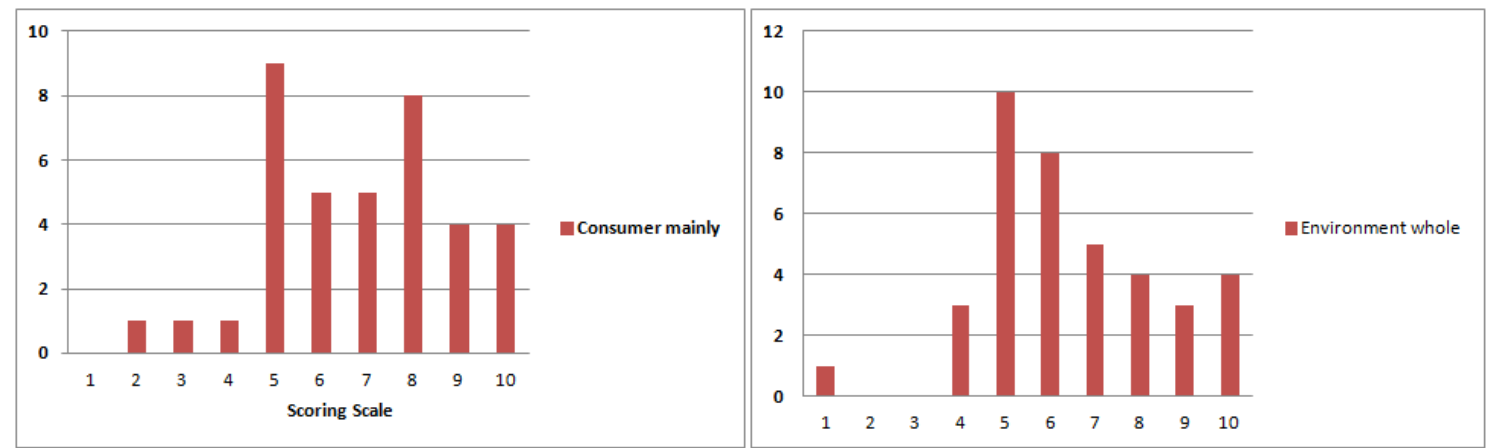

Figure 8. Consumer spending willingness on green product alternatives $(1=$ Least willing; $10=$ Most willing): (Left) Direct and immediate effects on the consumer; (Right) Affect the environment as a whole

\section{Summary and Conclusion}

In conclusion, the analysis of the data collected through survey questionnaires and in-depth interviews provide a beneficial understanding of consumer preferences and their spending patterns towards environmentally-friendly products.

The results of this paper illustrate that consumers, in general, prefer environmentally-friendly productswith more personal and financial benefits such as fuel-saving products and energy-efficient alternatives over the ones that mainly benefit the environment per se such as biodegradable or recycled products.

Although a large majority of consumers do see added valuein products that are promoted as environmentally friendly, however, not all customers are willing to spend extra for such products. The willingness to spend more on green product alternatives primarily depends on the price range of the product. Consumers under 35 years of age have different levels of willingness to spend more than those who are over 35. Males and females also differ in their willingness to spend more on these green alternatives. Consumers attribute different rankingsto different features of the product depending on product type and its positioning across the price spectrum: Brand, quality, price and convenience become more important than environmental- friendliness in higher-end more expensive product category items such as home appliances and electronics whereas forlower-end household 
product categories such as cleaning supplies and toiletries, the green feature of the product gets prioritized only over the brand but not over the quality.

The results of these analyses will eventually enable manufacturers to take advantage of the opportunities in development of eco-friendly products yielding to higher profit margins. They illustrate on where charging more for green is recommended and where it may compromise the sales revenues. These results provide insight to manufacturers, product developers and marketing companies in determining innovative development solutions, competitive pricingstrategies and comprehensive market initiatives towards green products and alternatives.

\section{Acknowledgments}

The authors would like to thank the MBA professors and graduate students of Concordia University John Molson School of Business in Montreal for their support and assistance in multiple phases of the survey data collection and interviews. Sincere appreciations are also due to Dr. Jamshid Etezadi, Professor of Supply Chain and Business Technology Management at Concordia University in Montreal, Canada for his valuable feedback and comments on through this work.

\section{References}

Schiffman, L. G., \& Kanuk, L. L. (2007). Consumer Behavior (9th ed.). Pearson Prentice Hall.

Webb, C., \& Esakin, T. C. (2011). A Green Economy for Canada: Consulting with Canadians. Canadian Institute for Environmental Law and Policy.

Global Sustainable Development Report: Building the Common Future We Want. (2013). Executive Summary, Division for Sustainable Development; United Nations Department of Economics and Social Affairs.

Devore, J. L. (2012). Probability and Statistics for Engineering and the Sciences (8th ed.). Brooks / Cole.

Forbes, C., Evans, M., Hastings, N., \& Peacock, B. (2011). Statistical Distributions (4th ed.). John Wiley and Sons.

\section{Copyrights}

Copyright for this article is retained by the author(s), with first publication rights granted to the journal.

This is an open-access article distributed under the terms and conditions of the Creative Commons Attribution license (http://creativecommons.org/licenses/by/3.0/). 